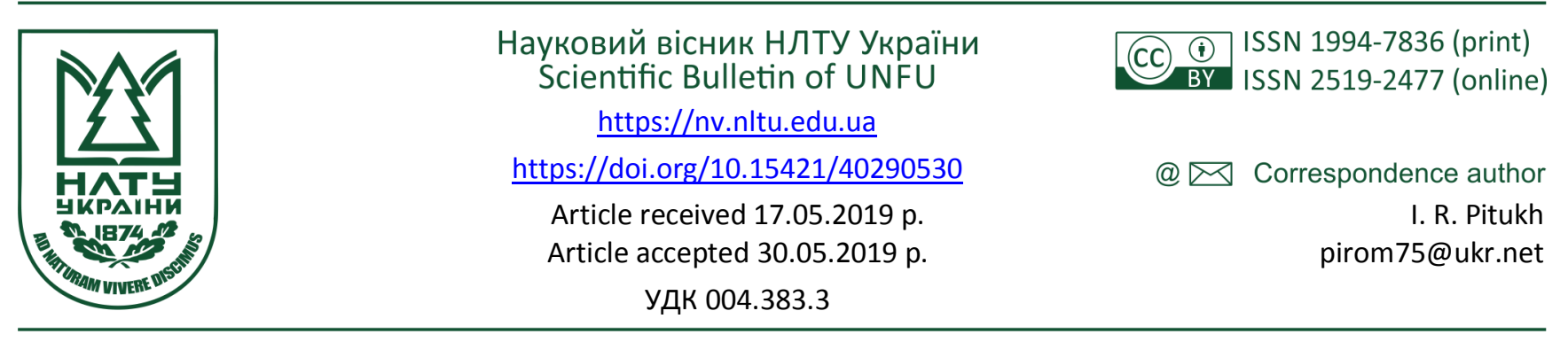

I. P. Пimyx

Тернопільський національний економічний університет, м. Тернопіль, Украйна

\title{
ПЕРСПЕКТИВИ ВДОСКОНАЛЕННЯ АЛГОРИТМІВ ОБЧИСЛЕННЯ ТА ПРОЦЕСІВ ПОБУДОВИ ІНФОРМАЦІЙНИХ ЛОГІКО-СТАТИСТИЧНИХ МОДЕЛЕЙ У БАЗИСІ ХААРА-КРЕСТЕНСОНА
}

\begin{abstract}
Розглянуто синтез структури образно-кластерної моделі інтерактивного моніторингу станів багатопараметричних об'єктів управління на основі системи автоматизованого проектування алгоритму розпаралеленого опрацювання статистичних даних та кореляційних характеристик технологічних об'єктів. Викладено теоретичні засади методології побудови образно-кластерної моделі багатопараметричних об'єктів. Розроблено теоретичні засади, методології та спосіб контролю параметрів технологічного процесу на основі образно-кластерної моделі, який дає змогу розширити функціональні можливості та підтримати інформативність процедур аналізу технологічних процесів контролем не тільки відхилень їх параметрів за амплітудою, але й відхилень статистичних значень: ковзного математичного сподівання, середньостатистичної динаміки ковзної структурної кореляції, матриці нормованих коефіцієнтів взаємокореляції між парами технологічних параметрів, логікостатистичних інформаційних, спектральних, кластерних та ентропійних моделей. Представлено структуру образно-кластерної моделі, яка враховує значну кількість контролюючих параметрів та їх кластерні представлення. Проведено аналіз статистичних і стохастичних методів оцінки значень параметрів, при цьому обгрунтовано використання логіко-статистичних інформаційних моделей для систематизації технологічних параметрів.
\end{abstract}

Ключові слова: оцінка інформативності; системи розпізнавання; структурна ідентифікація; кодування.

Вступ. Актуальною проблемою розв'язання комплексу наукових задач пов'язаних з розвитком теорії вдосконаленням методології та техніки побудови в інтерактивних комп'ютеризованих систем (ІРКС), є проблемно-орієнтована структуризація потоків даних та їх опрацювання програмно-апаратними засобами.

3 огляду на наявність широкого класу об'єктів управління, які характеризуються високим рівнем пожежної, вибухової та екологічної небезпеки особливу увагу під час визначення систем характеристик таких ІРКС приділяють забезпеченню їх високої надійності, живучості властивостей удосконалення та адаптації до екстремальних умов експлуатації. При цьому в інформаційному середовищі такого класу комп'ютеризованих систем зростають вимоги до рівня функціональної діяльності операторів (Pitukh et al., 2016a).

Основою класичної концепції є вимога, що інтерактивна система управління є багатометричним об'єктом i повинна проектуватись так, щоб вона була здатна успішно і достатньо надійно виконувати свої функції не тільки в умовах режиму "норма", але насамперед у невизначених квазістаціонарних та нестаціонарних екстремальних умовах перехідних, передаварійних та аварійних режимах (Pitukh et al., 2016b).

Запропонована розробка концепції теоретичних засад, методології та способу контролю параметрів технологічного процесу на основі образно-кластерної моделі
(ОКМ) дає змогу розширити функціональні можливості та підтримати інформативність процедур аналізу технологічних процесів контролем не тільки відхилень їх параметрів за амплітудою, але й відхилень статистичних значень: ковзного математичного сподівання, середньостатистичної динаміки ковзної структурної кореляції, матриці нормованих коефіцієнтів взаємокореляції між парами технологічних параметрів, логіко-статистичних інформаційних, спектральних, кластерних та ентропійних моделей (Nykolaichuk, 2008).

1. Концепція вирішення проблеми вдосконалення програмно-апаратних засобів інтерактивних та діалогових комп'ютеризованих систем і спосіб контролю технологічного процесу. Відомий спосіб (Patent Ukrainy, 2012), який містить циклічний вимір значень кожного параметра і їхн запам'ятовування, визначення стану технологічного процесу шляхом порівняння вимірюваних значень параметра в області можливих значень норми, ідентифікацію стану квазістаціонарного об'єкта, визначення структурної автокореляційної функції та нормованого коефіцієнта взаємокореляції, за якими порівнюють:

• ковзні статистичні характеристики математичного сподівання, згідно з виразами:

$$
L_{1}=\left\{\begin{array}{l}
0, \text { якщо } a_{1}<M_{j}<a_{2} ; \\
1, \text { якщо } a_{1} \geq M_{j} \geq a_{2},
\end{array}\right.
$$

Інформація про авторів:

Пітух Irор Романович, канд. техн. наук, доцент, кафедра спеціалізованих комп'ютерних систем.

Email: pirom75@ukr.net; https://orcid.org/0000-0002-3329-4901

Цитування за ДСту: Пітух І. Р. Перспективи вдосконалення алгоритмів обчислення та процесів побудови інформаційних логікостатистичних моделей у базисі Хаара-Крестенсона. Науковий вісник НЛтУ України. 2019, т. 29, № 5. С. 151-155.

Citation APA: Pitukh, I. R. (2019). The Prospects for Improving Algorithms of Computing and Processor Construction of Information Logic-Statistical Models in Haar-Krestenson basi. Scientific Bulletin of UNFU, 29(5), 151-155. https://doi.org/10.15421/40290530 
де: $M_{j}=\frac{1}{n} \cdot \sum_{i+j}^{n+j} x_{i+j}, i=1,2, \ldots, I, n-$ кількість контрольованих параметрів технологічного об'єкта;

- структурну кореляційну функцію, згідно з виразом

$$
L_{2}=\left\{\begin{array}{l}
0, \text { якщо } b_{1}<C_{x x}(j)<b_{2} ; \\
1, \text { якщо } b_{1} \geq C_{x x}(j) \geq b_{2},
\end{array}\right.
$$

де $C_{x x}(j)=\frac{1}{n} \cdot \sum_{i+j}^{n+j}\left(x_{i}-x_{i-j}\right)^{2}, j=\overline{0, m}$;

• коефіцієнти нормованої взаємокореляції між двома параметрами, згідно з виразом

$$
L_{3}=\left\{\begin{array}{l}
0, \text { якщо } 0<\rho_{x y}<1 ; \\
1, \text { якщо } 0 \geq \rho_{x y} \geq-1,
\end{array}\right.
$$

де $\rho_{x y}=\frac{R_{x y}(0)}{\sigma_{x} \cdot \sigma_{y}}, \sigma_{x}=\frac{1}{n} \sum_{i+j}^{n+j}\left(x_{i}-M_{x j}\right)^{2}, \sigma_{y}=\frac{1}{n} \sum_{i+j}^{n+j}\left(y_{i}-M_{y j}\right)^{2}$.

Удосконалений спосіб контролю параметрів технологічного процесу має розширені функціональні можливості та більшу інформативність (Patent Ukrainy, 2019). Такий спосіб містить циклічний вимір значень кожного параметра і їхнє запам'ятовування, визначення стану технологічного процесу шляхом порівняння вимірюваних значень параметра з граничними уставками, ідентифікацію стану квазістаціонарного об'єкта, визначення структурної автокореляційної функції та нормованого коефіцієнта взаємокореляції, за якими порівнюють ковзні статистичні характеристики математичного сподівання, в якому визначають:

- вибіркові математичні сподівання;

- зважені ковзні математичні сподівання параметрів, які дають змогу виконувати екстраполяцію та передбачення зміни станів технологічного процесу в часі;

- виконують порівняння амплітудних, динамічних, фазових та взаємокореляційних характеристик технологічного процесу на основі побудови логіко-статистичних інформаційних моделей;

- виконують порівняння спектральних характеристик вимірюваних значень параметрів в області можливих значень норми, згідно з виразами:

$$
L_{4}=\left\{\begin{array}{l}
0, \text { якщо } S_{1}<S_{w}<S_{2} ; \\
1, \text { якщо } S_{1} \geq S_{w} \geq S_{2} .
\end{array},\right.
$$

де: $S_{w}=\frac{1}{m} \sum_{j=1}^{m} \rho_{x x}(j) \cdot w_{j} \cdot e^{-\alpha \cdot j}, w-$ кругова частота косинусного перетворення Фур'є; $\rho_{x x}(j)=R_{x x}(j) / D_{x}-$ нормована і центрована автокореляційна функції контрольованого параметра технологічного процесу; $D_{x}=\sigma_{x}^{2}-$ дисперсія технологічного процесу; $R_{x x}(j)=\frac{1}{n} \sum_{i=1}^{n} \dot{x}_{i} \cdot \dot{x}_{i+j}-$ центрована автокореляційна функція параметра технологічного процесу, $\dot{x}_{i}=x_{i}-M_{x}$;

• визначають матрицю ймовірностей переходу технологічного процесу з одного стану в інший $P_{i j}$, де

$$
P_{i j}=\begin{array}{cccccc}
P_{11} & P_{12} & \cdots & P_{1 j} & \cdots & P_{1 n} \\
y_{21} & P_{22} & \cdots & P_{2 j} & \cdots & P_{2 n} \\
\cdots & \cdots & \cdots & \cdots & \cdots & \cdots \\
P_{i 1} & P_{i 2} & \cdots & P_{i j} & \cdots & P_{i n} \\
\cdots & \cdots & \cdots & \cdots & \cdots & \cdots \\
P_{m 1} & P_{m 2} & \cdots & P_{m j} & \cdots & P_{m n}
\end{array},
$$

де: $P_{i j}$ - ймовірнісний стан норми; $P_{i j}$ - ймовірнісний стан прогнозу різних видів передаварійних станів, $P_{i j}-$ ймовірнісний стан аварії, $i=\overline{1, m}, j=\overline{1, n}$;

- здійснюють оцінку кореляційної ентропії технологічного процесу, яка відображає деградацію кореляційних характеристик технологічного процесу і передбачає розвиток передаварійних станів технологічного процесу, згідно з виразом

$$
I_{x}=n \cdot \hat{E}\left[\frac{1}{2} \log _{2} \frac{1}{m} \sum_{j=1}^{m}\left(D_{x}^{2}-R_{x x}^{2}(j)\right)\right],
$$

де: $m$ - кількість точок автокореляційної функції, $\hat{E}[\bullet]$ - цілочисельна функція з округленням до більшого цілого;

• здійснюють оцінку імовірнісної міри ентропії згідно з виразом

$$
I_{x}=-\sum_{i=1}^{m} P_{i}, \log _{2} P_{i},
$$

де $P_{i}$ - ймовірність випадкового повідомлення;

- формують еталонне зображення образно-кластерної моделі стану технологічного процесу "норма", додатково порівнюють параметри еталонного стану з виміряними, спостережуваними та розрахованими параметрами технологічного процесу "норма", "прогноз аварії" та "аварія" та ідентифікують стан технологічного процесу додатковим відображенням на моніторі оператора структуризованої образно-кластерної фейс-моделі.

2. Функціональна структура та характеристики комп'ютеризованої системи контролю технологічного процесу. Підвищення інформативності відображення ОКМ технологічного стану об'єкта управління (ОУ) досягається додатковим супроводженням стилізованої фейс-моделі об'єкта аудіо-повідомленнями про конкретизований характер відхилення технологічного процесу від норми, а також інтерфейсними діалоговими інструкціями та рекомендаціями щодо виведення об'єкта 3 нештатного стану (Patent Ukrainy, 2019).

На рис. 1 подано структуру системи контролю технологічного процесу, яка реалізує відображення та аудіо супроводження результатів обчислень інформаційних моделей стану ОУ.

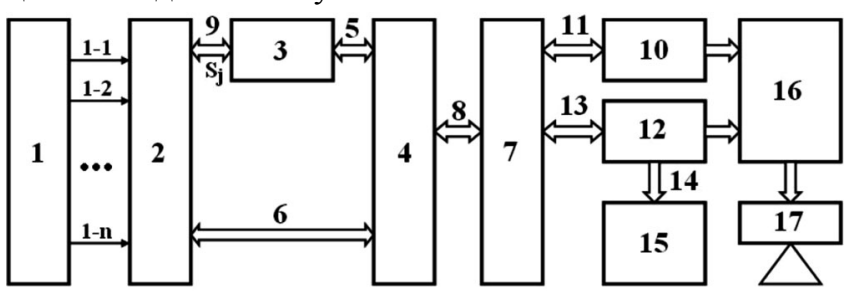

Рисунок. Структура системи контролю технологічного процесу

Запропонована система контролю параметрів технологічного процесу містить циклічний вимір параметрів $1,1-2, \ldots$ 1-n, блок збирання інформації 2, до інформаційного входу якого підключені давачі $1-1,1-2, \ldots$ 1-n, пульт оператора 3, пристрій підготовки інформації 4, першу шину 5, що з'єднує пристрій підготовки інформації 4 і пульт оператора 3, другу шину 6, що з'єднує пристрій підготовки інформації 4 і блок збирання інформації 2, блок введення інформації 1, третю шину 8 , що з'єднує блок виведення інформації 7, і пристрій підготовки інформації 4, шину 9, що з'єднує пульт оператора 3 і блок збирання інформації 2; яка містить постійний запам'ятовуючий пристрій (ПЗП) 10, вхід якого з'єднаний шиною 11 та першим виходом блоку виводу 
7, а вихід ПЗП 10 з'єднаний з першим входом блоку порівняння 12, другий вхід якого з'єднаний шиною 133 другим виходом блоку виводу 7, а вихід з'єднаний шиною 14 з монітором оператора 15, на якому відображається образно-кластерна модель, містить блок комутації аудіо повідомлень 16, перший вхід якого з'єднаний 3 другим виходом ПЗП 10, другий вхід з'єднаний 3 другим виходом блоку порівняння 12, а вихід з'єднаний 3 випромінювачем звукових сигналів 17.

В основу побудови ОКМ поставлено розрахунок у реальному масштабі часу характеристик інформаційних моделей згідно з функціоналом:

$$
X_{T \Pi}=F\left(\left\{x_{i}\right\},\left\{y_{i}\right\}, S_{o y}, M_{x}, M_{j}, M_{v}, D_{x}, \delta_{x}, R_{x x}, S_{w}, L_{i}, \rho_{i j}, I_{x}\right),
$$

де: $\left\{x_{i}\right\},\left\{y_{i}\right\}$ - масиви оцифрованих моніторингових даних параметрів ОУ; $S_{o y}$ - відповідно семантичний, інформаційний та технологічний стани $\mathrm{OУ} ; M_{x}, M_{j}, M_{v}-$ відповідно вибіркове, ковзне та вагове математичні сподівання; $D_{x}, \delta_{x}$ - відповідно дисперсія та середньоквадратичне відхилення; $R_{x x}$ - автокореляційна функція; $S_{w}$ - спектри параметрів ОУ у різних теоретико-числових базисах; $L_{i}$ - логіко-статистичні інформаційні моделі (ЛСІМ), $i \in \overline{1,5} ; \rho_{i j}-$ матриця коефіцієнтів взаємокореляції; $I_{x}$ - кореляційна міра ентропії стану ОУ.

Як образно-кластерне відображення динаміки станів "норми", "прогноз аварії" та "аварії" технологічного процесу на моніторі оператора формується структуризована образно-кластерна модель динамічних слайдів стилізовано наближених до ознак обличчя (фейс-моделі) людини 3 циклічним оновленням слайдів в реальному часі.

Принцип побудови структуризованої образно-кластерної моделі полягає в тому, що в особливих точках монітору, наближених до структуризованого зображення обличчя людини, формуються статичні або динамічні дворівневі чи кольорові символи, що відображають динаміку виміряних та розрахованих параметрів технологічного процесу. При цьому зображення образнокластерної моделі (рис., $a, \sigma, \varepsilon)$ відповідно відображають стани технологічного процесу - "норма", "прогноз аваріi" та "аварія". Відображення на моніторі оператора образно-кластерної моделі технологічного процесу у стані "норма" $є$ еталонним, яке задається постійним запам'ятовуючим пристроєм, порівнюється з виміряними, спостережуваними та розрахованими параметрами технологічного процесу і динамічно відображається на моніторі оператора. При зміні виміряних та розрахованих параметрів технологічного процесу у відповідних позиціях образно-кластерної фейс-моделі відбувається реструктуризація образно-кластерного відображення станів технологічного процесу, відповідно "норма", "прогноз аварії" та "аварія".

Відображення ОКМ на моніторі оператора повинно здійснюватися згідно 3 вимогами ергономіки 3 кроком часової дискретизації в межах 0,8-2,4 с. Тому до швидкодії процесорів, які реалізують алгоритми обчислень та побудови інтерактивних моделей ОУ, ставляться жорсткі вимоги максимальної швидкодії. Успішне вирішення цієї проблеми може бути досягнуте глибоким розпаралеленням алгоритмів обчислень інформаційних моделей, максимальним спрощенням математичних перетворень та забезпеченням максимальної швидкодії опрацювання цифрових даних системою відповідних спец процесорів.

Оскільки застосування універсальних мікроконтролерів 3 обмеженими функціональними можливостями щодо розпаралелення обчислювальних процесів, а також відсутність необхідної кількості аналого-цифрових перетворювачів, співпроцесорів та прискорювачів обчислювальних операцій в принципі не дає змогу вирішити цю задачу в реальному масштабі часу (Nykolaichuk, 2012). Окрім цього, виключене застосування перетворення двійкової системи числення в універсальних обчислювальних засобах не дає змогу реалізувати високопродуктивні алгоритми обчислень на основі модульної арифметики системи залишкових класів та спец процесорів в базисі Хаара-Крестенсона.

3. Розпаралелені алгоритми побудови інформаційних образно-кластерних моделей. Розпаралелений алгоритм побудови ОКМ представимо у вигляді системи графів:

1. Аналого-цифрове перетворення сигналів сенсорів та формування по кожному параметру оцінок математичних сподівань центрованих значень, дисперсії та середньоквадратичного відхилення

$$
\left.\begin{array}{c}
x_{1}(t) \rightarrow \\
\ldots \\
x_{k}(t) \\
\ldots \\
x_{p}(t)
\end{array}\right\}\left\{\left\{x_{i k}\right\} ; i \in \overline{1, n} ; k \in \overline{1, m} ;\left\{\begin{array}{l}
\left(M_{x k}\right) ; \\
\left\{\dot{x}_{i k}=x_{i k}-M_{x k}\right\} ; \\
D_{x j}=\overline{\dot{x}_{i k}^{2}} ; \\
\delta_{x k}=\sqrt{D_{x k}} .
\end{array}\right.\right.
$$

2. Визначення оцінок дискретних функцій авто- та взаємокореляції між парами технологічних параметрів та матриці нормованих коефіцієнтів взаємокореляції

$$
\left\{x_{i l}\right\} \rightarrow \begin{cases}H_{x x}(j) & H_{x y}(j) \\ P_{x x}(j) & P_{x y}(j) \\ K_{x x}(j) & K_{x y}(j) \\ R_{x x}(j) & R_{x y}(j) \quad j \in 0, \\ \rho_{x x}(j) & \rho_{x y}(j) \\ C_{x x}(j) & C_{x y}(j) \\ G_{x x}(j) & G_{x y}(j) \\ F_{x x}(j) & F_{x y}(j)\end{cases}
$$

3. Визначення спектрів у різних теоретико-числових базиcax (ТЧБ)

$$
\left.\begin{array}{rl}
\left\{x_{i 1}\right\} & \rightarrow \\
\ldots & \\
\left\{x_{i k}\right\} & \rightarrow \\
\ldots \\
\left\{x_{i p}\right\} & \rightarrow
\end{array}\right\} \begin{aligned}
& S\left(w_{1}\right) \rightarrow \text { ТЧБ Фур'є } \\
& S\left(w_{2}\right) \rightarrow \text { ТЧБ Радемахера } \\
& S\left(w_{3}\right) \rightarrow \text { ТЧБ Хаара } \\
& S\left(w_{4}\right) \rightarrow \text { ТЧБ Крестенсона }
\end{aligned}
$$

4. Визначення логіко-статистичних інформаційних моделей (ЛСІМ)

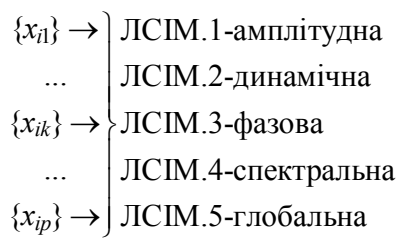

4. Метод удосконалення структури ПОД шляхом оптимізації кодування телеметричних та алфавітноцифрових даних. Відомо, що амплітуди аналогових сигналів сенсорів у дистрибутивних КМ стандартизовані у діапазонах (Stadnyk, 2005): 0-5 мA; 5-20 мА; 0-1 B; 1-10 B; 0-2 кГц та ін. Аналогові сигнали сенсорів на 
низових рівнях комп'ютеризованих систем (КС) перетворюються у цифрові телеметричні дані АЦП з відповідною розрядністю у діапазонах 2 к, які забезпечують відповідну точність представлення цифрових відліків згідно відповідного класу точності сенсорів.

Для діапазонів змін амплітуд аналогових сигналів сенсорів: $(1 ; 2 ; 5 ; 10 ; 20)$ В відповідно застосовуються АЦП з розрядністю: $(6-8 ; 8-12 ; 12-16 ; 16-24)$ біт. Основними виробниками АЦП є фірми Техас інст., Analog Devices iн. Аналіз показує, що реєстрація стандартних сигналів сенсорів АЦП з вихідними кодами двійкової системи числення $є$ надлишковим, оскільки цифрові значення двійкових кодів у діапазонах, наприклад: (101-127; 201-255; 1001-1023; 4001-4095) не використовуються у процесі кодування телеметричних даних. У стандартних ПОД такі дані кодуються 7-розрядними та 8-розрядними кодами у структурі фрейма дані та зміст кадру.

Дослідження таких діапазонів двійкових кодів телеметричних даних показує, що цифрові 7-бітні телеметричні дані у діапазоні (0-99) одиниць представляються двійковими кодами у діапазоні (0000000-1100011).

Тобто коди $11 \times x \times 11$, де х є 0.1 , можуть бути застосовані для кодування 7-бітних регістрових, наприклад стартстопних або інших службових даних, у структурі ПОД. Окрім цього, у структурі змісту даних, у якості розділових обмежуючих кодів, можуть бути ефективно застосовані двійкові коди чисел у діапазоні (11001001111111) з ознаками парності:
$(100,102,104, \ldots, 126)$;
$(101,103,105, \ldots, 127)$;
$(1100100 \div 1111110)$;
$(1100101 \div 1111111)$.

У цьому випадку легко організовується 8-бітний потік даних з можливістю виявлення однократних помилок.

Аналогічне формування регістрових та службових кодів отримаємо у діапазоні квантування сигналів сенсорів $(0 \div 255)$ класу $0,5 \%$. Тобто коди телеметрії 8-біт будуть представлені у діапазоні двійкових чисел (00000000-11000111), а коди у діапазоні відповідно (11001000-11111111) застосовані у якості регістрових та службових даних. Коди телеметрії 12-біт у діапазоні

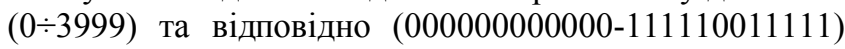
дають змогу формувати три регістрові коди шляхом заміни двох нулів кодами $(01,10,11)$ та отримати 92 службових коди починаючи з $111110100000(2)=4000(10)$ до граничного коду (111111111110).

Існує багато прикладів застосування алфавітів символів, кількість яких не дорівнює числам 2k. Наприклад, таблиці кольороутворення RGB-стандарту (Melnyk, 2008) у вигляді табл. $16 \times 12$, а також алфавіту (Vozna, 2018). Прикладом застосування такої технології є формування символів стандартного коду ASCII згідно із 7бітними регістровими кодами з 95-символьним алфавітом у кожному регістрі:

- $\mathrm{R}_{1}$ (1100111) - символи (32 $\left.\div 127\right)$;

- $\mathrm{R}_{2}$ (1101011) - символи $(32 \div 64),(96 \div 127)$;

- $\mathrm{R}_{3}(110111)$ - символи $(32 \div 64),(192 \div 295)$;

- $\mathrm{R}_{4}(1110011)$ - символи $(32 \div 64),(224 \div 253)$;

- $\mathrm{R}_{5}(1110111)$ - символи $(32 \div 127),(128 \div 191)$;

- $\mathrm{R}_{6}(1111011)$ та $\mathrm{R}_{7}(1111111)$ - резерв.

У структурі стандартних ПОД об'єм інформаційних АЦД практично становить більше 90 \% об'єму пакету. Тому зменшення бітової та байтової ємності цього змістовного компонента структури ПОД $є$ актуальною прикладною задачею.
Застосування дослідженого ефекту надлишковості двійкового кодування телеметричних даних до технології кодування таблиць алфавітів АЦД дає змогу значно розширити функціональні можливості удосконалених структур фреймів ПОД, зокрема вилучити операцію біт-стаффінга, наявність якої приводить до невизначеності довжини пакетів, що не дає змогу виявити на прийомі вставки та стирання бітів, які можуть виникати на фізичному рівні КМ під впливом завад. Передавання байт-орієнтованих даних із швидкісю 8 бод/с потребує застосування 28-арного ансамблю сигналів. Це, водночас, потребує якісних каналів зв'язку. Тому зменшення розрядності кодів фрейму ПОД до 6-ти та 4-ох бітів $є$ важливою умовою зменшення кількості сигналів в ансамблі відповідно до 64-ох та 16-ти, що дає змогу істотно зменшити вимоги до каналів зв'язку. Окрім цього, для формування АЦД ефективно може бути застосована 16-символьна синтезуюча клавіатура 3 двократним формуванням 4-бітних компонентів символів (Patent Ukrainy, 2015).

У табл. 1 наведено приклад структур ПОД згідно із запропонованою технологією із 7-бітних потоків даних. Фрейм такого ПОД відповідає структурі кадру стандартного протоколу HDLC.

Табл. 1. Класи точності сенсорів та розрядності АЦП

\begin{tabular}{|c|c|c|c|c|c|c|c|c|c|c|c|c|c|}
\hline $\mathrm{F}$ & \multicolumn{3}{|c|}{$\mathrm{A}_{1}$} & \multicolumn{3}{|c|}{$\mathrm{A}_{2}$} & \multicolumn{3}{|c|}{$\mathrm{Y}$} & \multicolumn{3}{|c|}{ ADD } & $\mathrm{F}$ \\
\hline 11 & 0 & & 1 & 0 & & 1 & 0 & & 1 & 0 & & 1 & 11 \\
\hline 11 & 0 & & 1 & 0 & & 1 & 0 & & 1 & 0 & & 1 & 11 \\
\hline 11 & 0 & - & 0 & 0 & - & 0 & 0 & - & 0 & 0 & - & 0 & 11 \\
\hline 11 & 0 & - & 0 & 0 & - & 0 & 0 & - & 0 & 0 & - & 0 & 11 \\
\hline 11 & 0 & - & 0 & 0 & - & 0 & 0 & - & 0 & 0 & - & 0 & 11 \\
\hline 11 & 0 & & 1 & 0 & & 1 & 0 & & 1 & 0 & & 1 & 11 \\
\hline 00 & 0 & & 1 & 0 & & 1 & 0 & & 1 & 0 & & 1 & 00 \\
\hline
\end{tabular}

У табл. 2 наведено структури та характеристики запропонованих удосконалених ПОД з 8 -ми, $2 \times 6$-, та $3 \times 4$ бітними інформаційними потоками.

Табл. 2. Структури фреймів, удосконалених ПОД (біт)

\begin{tabular}{|c|c|c|c|c|c|c|}
\hline $\begin{array}{c}\text { Тип } \\
\text { ПОД }\end{array}$ & $\begin{array}{c}\mathrm{F} \\
8-16\end{array}$ & $\begin{array}{c}\mathrm{DA} \\
32\end{array}$ & $\begin{array}{c}\mathrm{SA} \\
32\end{array}$ & $\begin{array}{c}\mathrm{FC} \\
8\end{array}$ & $\begin{array}{c}\mathrm{PDU} \\
\mathrm{m} \times 8\end{array}$ & $\begin{array}{c}\mathrm{F} \\
8-16\end{array}$ \\
\hline 8 & $\mathrm{~F}_{1} 16$ & $5 \times 8$ & $5 \times 8$ & $2 \times 8$ & $\mathrm{~m}_{1} \times 8$ & $\mathrm{~F}_{1} 16$ \\
\hline $2 \times 6$ & $\mathrm{~F}_{2} 12$ & $6 \times 6$ & $6 \times 6$ & $2 \times 6$ & $\mathrm{~m}_{2} \times 12$ & $\mathrm{~F}_{2} 12$ \\
\hline $3 \times 4$ & $\mathrm{~F}_{3} 12$ & $(3 \times 4) \times 3$ & $(3 \times 4) \times 3$ & $3 \times 4$ & $\mathrm{~m}_{3} \times 12$ & $\mathrm{~F}_{3} 12$ \\
\hline
\end{tabular}

У табл. 2 застосовані коди флагів, які використовують у стандартних ПОД типу HDLC: $\mathrm{F}_{1}-$ (11111111.01111110); $\quad \mathrm{F}_{2}-\quad$ (111101.111110); $\quad \mathrm{F}_{3}-$ (1111.0111.1110). Розрядність кодів DA та SA вибирається так, щоби п'ять 7-бітних інформаційних кодів 3 обмеженням діапазону $(0 \div 200)$ та $(0 \div 4000)$ та три 12 бітні коди з обмеженням інформаційних значень у діапазоні $(0 \div 4000)$ не зменшували стандартну розрядність 32 біта. Аналогічно розраховуються числа $\mathrm{m}_{1}, \mathrm{~m}_{2}$, $\mathrm{m}_{3}$ для PDU.

Висновок. Вдосконалення алгоритмів обчислення та процесорів побудови інформаційних логіко-статистичних моделей дає змогу збільшити функціональні можливості й інформативність способу контролю параметрів технологічного процесу та формування еталонного зображення образно-кластерної моделі стану технологічного процесу "норма", порівняння параметрів еталонного стану з виміряними, спостережуваними та розрахованими параметрами технологічного процесу "норма", "прогноз аварії" та "аварія", ідентифікацію стану технологічного процесу відображенням на моніторі оператора образно-кластерної моделі, що дає змогу додатково підвищити швидкодію реакції оператора на відхи- 
лення технологічного процесу від норми та попередити виникнення його аварійних станів.

\section{Перелік використаних джерел}

Melnyk, A. O. (2008). Arkhitektura kompiutera. Lutsk: Volyn Regional Printing House, 470 p. [In Ukrainian].

Nykolaichuk, Ya. M. (2008). Teoriia dzherel informatsii. Ternopil TNEU, 536 p. [In Ukrainian].

Nykolaichuk, Ya. M. (2012). Kody polia Halua: Teoriia ta zastosuvannia. Ternopil: TzOV "Terno-hraf", 576 p. [In Ukrainian].

Patent Ukrainy. (2012). Patent Ukrainy na korysnu model №71122. Sposib kontroliu parametriv tekhnolohichnoho protsesu 10.07.2012 r., Biul. № 13. [In Ukrainian].

Patent Ukrainy. (2015). Patent Ukrainy na korysnu model №107904. Prystrii dlia vvedennia alfavitno-tsyfrovykh danykh - 25.02.2015 r., Biul. № 4. [In Ukrainian].

Patent Ukrainy. (2019). Patent Ukrainy na korysnu model № 134154. Sposib kontroliu parametriv tekhnolohichnoho protsesu 10.05.2019 r., Biul. № 9. [In Ukrainian].
Pitukh, I. R., Vozna, N. Ya., Protsiuk, H. Ya., \& Nykolaichuk, Ya. M. (2016a). Metod pryiniattia rishen strukturyzovanoi identyfikatsii staniv promyslovykh obiektiv $\mathrm{v}$ interaktyvnykh kompiuteryzovanykh systemakh. Pratsi VIII Mizhnarodnoi shkoly-seminaru "Teoriia pryiniattia rishen", (pp. 64-65). Uzhhorod: UzhNU. [In Ukrainian].

Pitukh, I., Nykolaychuk, L., Protsiuk, H., \& Protsiuk, V. (2016b). Information and Legal Aspects of the Communication Functions of the Computerized System Operator. Modern Problem of Radio Engineeriong, Telecommunikations and Computer Science: Proceedings of the XIIIth International Conference TSET2016, February 23-26, (pp. 885-888).

Stadnyk, B. I. (Ed.). (2005). Fundamentals of Metrology and Measuring Technology. (Vol. 2). Lviv: NU Lvivska Politechnika, $656 \mathrm{p}$.

Vozna, N. Ya. (2018). Strukturyzatsiia polifunktsionalnykh danykh: teoriia, metody ta zasoby. Ternopil: TNEU, 378 p. [In Ukrainian].

Ternopil National Economic University, Ternopil, Ukraine

\section{THE PROSPECTS FOR IMPROVING ALGORITHMS OF COMPUTING AND PROCESSOR CONSTRUCTION OF INFORMATION LOGIC-STATISTICAL MODELS IN HAAR-KRESTENSON BASI}

The work is devoted to the synthesis of the structure of the figurative cluster model of interactive monitoring of the states of many parametric control objects on the basis of the system of automated designing of the algorithm of parallel processing of statistical data and correlation characteristics of technological objects. The theoretical principles of the methodology of constructing a figurative cluster model of multi-parameter objects on the basis of the proposed functional of the state of the monitoring object are described. Structural solutions of computerized control systems of technological process parameters are analyzed. The functions of interaction of the operator in the informational environment of the computerized system are systematized. The structure of the parallel algorithm for constructing and displaying the image-cluster object model on the monitor based on the developed software is presented. The theoretical principles, methodology and method of control of the technological process parameters based on the figurative cluster model are developed, which allows expanding the functional capabilities and supporting the informativeness of the procedures of analysis of technological processes by controlling both the deviations of their parameters in amplitude, and also deviations of statistical values such as sliding mathematical expectation, statistical dynamics of sliding structural correlation, matrix of normalized coefficients of correlation between pairs of technological parameters, log ICO-statistical information, spectral, cluster and entropy models. The use of the list of indicators for control of the parameters characterizing the current state of the object of control in real time is determined. The mathematical model of construction of logical-statistical information models is presented and adapted to the figurative cluster model in the context of separate segments. The structure of a figurative cluster model is presented, which considers a large number of control parameters and their cluster representations. The analysis of statistical and stochastic methods of estimating the values of parameters is carried out, and the use of logical-statistical information models for systematization of controlled technological parameters is substantiated.

Keywords: informative evaluation; recognition system; structural identification; coding. 